\title{
Effect of Counselling and Reminder Text Messages Follow-Up on Adherence to Antiretroviral Therapy in Hajiya Gambo Sawaba General Hospital, Zaria, Nigeria
}

\author{
Mustapha A. Alfa ${ }^{1 *}$, A. U. Zezi ${ }^{2}$, S. S. Gyang ${ }^{3}$, H. Yusuf ${ }^{4}$, I. M. Aliyu ${ }^{2}$ \\ Departments of ${ }^{1}$ Clinical Pharmacy and Pharmacy Practice, Gombe State University, Gombe State, Nigeria. ${ }^{2}$ Pharmacology and Therapeutics, Ahmadu \\ Bello University, Zaria, Kaduna State, Nigeria. ${ }^{3}$ Pharmacology, University of Jos, Plateau State Nigeria. ${ }^{4}$ Clinical Pharmacy and Pharmacy Administration, \\ University of Maiduguri, Nigeria.
}

\section{ARTICLE INFO}

Article history:

Received on: 01/03/2016

Revised on: 18/04/2016

Accepted on: 24/06/2016

Available online: 26/09/2016

Key words:

Antiretroviral therapy, Adherence Counselling Text messages, Follow-up CD4, Self Report.

\begin{abstract}
Poor adherence is a major challenge to antiretroviral therapy. It is now recommended that patients have $95 \%$ adherence in order to maintain sufficient suppression of viral replication and prevent the emergence of resistance. It is therefore of paramount importance device methods to improve patient adherence. The use of mobile phone calls and text messages are being explored in improving adherence. In this study, the effect of counselling plus reminder text messages were determined. A total of 132 patients was allocated into an intervention and control groups. Both groups were given additional adherence counselling at the beginning of the study and at every clinic visit. The intervention group was also sent reminder text messages for a period of 24 weeks. The CD4 count of all patients was recorded at the start of the study, then the final reading after the follow-up period. The difference in the increase in the CD4 counts between the two groups was compared to find out the difference. Additionally, patients' self-report of adherence was compared between the two groups. Patients with 95\% and above adherence were classified as adherent, while those with less than 95\% nonadherent. It was found that the patients who received reminder text messages in addition to counselling had significantly higher mean percentage increase in CD4 count (36.7\%) compared to the control group (19.12\%), which received counselling only $(\mathrm{p}=0.007)$ However, using self-report form, there was no statistical significant difference in the level of adherence between intervention group and control group. It was therefore concluded that regular counselling and reminder text messages have improved adherence to antiretroviral therapy.
\end{abstract}

\section{INTRODUCTION}

Human immunodeficiency virus (HIV) is a single stranded RNA retrovirus that causes acquired immune deficiency syndrome (AIDS), a condition in which individuals are at increased risk of developing a group of clinical features including certain infections (opportunistic infections) and malignancies (Charles and Robert, 1997). Globally, 34.0 million people were living with HIV at the end of 2011. Sub-Saharan Africa remains

\footnotetext{
* Corresponding Author Department of Clinical Pharmacy and Pharmacy Practice, Faculty of Pharmaceutical Sciences, Gombe State University, Gombe State, Nigeria.Email: fasmural@gmail.com
}

most severely affected, with nearly 1 in every 20 adults (4.9\%) living with HIV and accounting for $69 \%$ of the people living with HIV worldwide. Worldwide, the number of people newly infected continues to fall (UNAIDS, 2012). Similarly, based on projected HIV estimates of 2013, about 3,229,757 people now live with HIV in Nigeria while it is estimated that 220,394 new HIV infections occurred in 2013 (NACA, 2014). Worldwide, non-adherence to antiretroviral therapy in adult HIV infected population ranges from 33-88 percent (Mills et al., 2006). Adherence is a very important issue in HIV management. Current findings suggest that patients must take a high proportion (95\% or more) of antiretroviral drug doses to maintain suppression of viral replication to non-detectable levels, that failure rates increase as adherence decrease, and that lack of strict adherence leads to clinical progression to AIDS (Pradier et al, 2003). 
The aim of the study is to assess the effect of text message follow-up and counselling on adherence to antiretroviral therapy. The hypothesized that text message follow-up and additional counselling will improve patients' adherence and will result in a good increase in CD4 counts. Many studies showed that mobile-based interventions to improve adherence to antiretroviral therapy (ART) are being explored and are useful in improving adherence. Study in the United States found that intervention strategy involving one-on-one pharmacist session providing adherence advice with follow-up telephone calls increased adherence level by pill count and self report (Simoni et al., 2003). Short weekly text messaging was also associated with ART adherence and viral load suppression (Horvath et al., 2012). Study in Kenya revealed that patients who received short message service had significantly improved ART adherence rates and viral load suppression (Lester et al., 2010). A study in a tertiary institution showed that monthly adherence counselling and twice weekly text messages reminder improved ART adherence (Maduka and Tobin-West, 2013). This study utilize short reminder text message to improve patients' adherence to ART. Therefore it is necessary to study the impact of text message follow-up on adherence to ART in this health facility as it is resource limited facility and serves a large community. Also no study of such type was conducted in this facility.

\section{MATERIALS AND METHODS}

\section{Materials}

Phones, pens, adherence assessment charts, plain sheets of paper.

\section{Methods}

A follow-up study using quantitative and semi-qualitative methods comparing ART adherence of HIV infected patients on HAART (highly active antiretroviral therapy) for more than six months, who receive twice weekly short reminder messages and those who do not receive messages.

\section{Study place}

The study was carried out at the ART clinic of Hajiya Gambo Sawaba General Hospital, Zaria, Kaduna State, Nigeria. The clinic serves many communities and Local Governments within Kaduna State including neighbouring states like Katsina and Kano. The clinic also has ART specialists comprising physicians, pharmacists and nurses. There are also adherence counsellors. Patients' medical and pharmacy records are available and there exist laboratories for monitoring patients CD4 counts and other patient specific parameters.

\section{Inclusion and exclusion criteria}

Only adults (both sexes) of 16 years and above were included in the study. Also only patients that have been on HAART (treatment-experienced patients) for six months and above, have undergone adherence counselling and able to read were included. Patients excluded from the study are pregnant women and children, patients that are just commencing HAART (treatment-naive patients), hospitalized patients and those that cannot read.

\section{Study design}

153 patients were recruited for the study. This sample size was determined by the formula;

$$
\mathrm{n}=[\mathrm{z} / \Delta]^{2} \mathrm{p}(1-\mathrm{p})(\text { Ahmad et al., 2012). }
$$

The patients were divided into two groups (A and B). Group A having 84 subjects was the intervention while group B (standard care i.e. received only counseling but no text messages) having 69 subjects the control group. The base-line characteristic of all participants was obtained from the patients' folders. Both groups received counselling on every clinic visit. Group B was followed- up for 24 weeks by sending text messages twice a week which was expected to improve patients' treatment outcome by both reminding them to take their drugs and provide support to the patients. The text messages were sent on Mondays and Thursdays. The content of the message was "Atuna, Ayi niyya" (meaning remember), "Remember to take it (Pharmacy department)".

The patients' CD4 counts were taken at baseline and also at the end of the 24 weeks' follow-up. The increase in the CD4 counts between the two groups was then compared to determine whether there was significant difference. In addition, both groups were given charts onto which the patient ticks whenever the medication is taken. If the patient takes the drug on time, he/she ticks in the space provided. But if more than an hour late or misses the dose, the space is left blank. On the clinic appointment day, which is usually on monthly or two monthly bases, patient report and charts were examined to compare the extent of adherence between the two groups. Adherence was dichotomized to define adherent at $95 \%$ and above and non-adherent at less than $95 \%$.

\section{Ethical consideration}

Permission to carry out the research was sought through the hospital ethics committee at the Kaduna State Ministry of Health. After the approval was obtained, verbal and written consent of the sample patients in the presence of a witness was sought after the purpose of the research was clearly explained to them.

\section{Adherence assessment}

After 24 weeks of follow-up, the difference in the increase in CD4 count between the two groups was determined. The percentage increase in CD4 count for each patient was calculated by the formula;

$\%$ increase in CD4 count $=\frac{\text { Final CD4 count }- \text { Base }- \text { line } \mathrm{CD} 4 \text { count } \times 100}{(\text { Final } C D 4 \text { count })}$

Charts and self report forms were used to determine ART adherence of the subjects. The charts were examined to see the number of doses that were missed or taken late. The verbal self 
report was carried out to reinforce the result of the chart. The patients were asked the number of doses they missed or taken more than an hour late from the time it was to be taken.

Percentage adherence for each patient was calculated by dividing the total number of doses taken by the total doses expected and multiplying by 100 .

\section{Total doses taken X 100}

Total doses expected to be taken

\section{Statistical analysis}

Data generated were entered into SPSS (statistical package for social sciences) version 20 to obtain the descriptive statistics. Student-t test and Chi-squared test were used make comparisons between the two groups. $\mathrm{P}$ value of $<0.05$ was considered significant in all statistical analysis.

\section{RESULTS}

\section{Socio-demographic Characteristics}

The socio-demographic characteristics of the patients are presented on table 1 . Out of the 153 patients recruited for the study, 21 patients in the intervention group did not receive text messages and thus excluded. Therefore, the socio-demographic characteristics represent that of 132 patients. The intervention and control groups had 63 and 69 patients respectively.

\begin{tabular}{|c|c|c|}
\hline $\begin{array}{l}\text { Participants' } \\
\text { Characteristics }\end{array}$ & $\begin{array}{l}\text { Intervention }(\mathrm{N}=63) \\
\text { Total }(\%)\end{array}$ & $\begin{array}{l}\text { Control }(\mathrm{N}=69) \\
\text { Total }(\%)\end{array}$ \\
\hline \multicolumn{3}{|l|}{ Sex } \\
\hline Male & $17(26.9)$ & $19(27.5)$ \\
\hline Female & $46(73.0)$ & $50(72.5)$ \\
\hline \multicolumn{3}{|l|}{ Age group } \\
\hline $16-30$ & $19(30.2)$ & $19(27.5)$ \\
\hline $31-40$ & $25(39.7)$ & $33(47.8)$ \\
\hline $41-50$ & $14(22.2)$ & $14(20.3)$ \\
\hline $51-60$ & $4(6.3)$ & $1(1.4)$ \\
\hline$>60$ & $1(1.6)$ & $2(2.9)$ \\
\hline \multicolumn{3}{|l|}{ Religion } \\
\hline Islam & $50(79.4)$ & $54(78.3)$ \\
\hline Christianity & $13(20.6)$ & $15(21.7)$ \\
\hline \multicolumn{3}{|l|}{ Marital status } \\
\hline Married & $50(79.4)$ & $48(69.6)$ \\
\hline Single & $4(6.3)$ & $9(13.0)$ \\
\hline Divorced & $3(4.7)$ & $3(4.3)$ \\
\hline Widowed & $6(9.5)$ & $9(13.0)$ \\
\hline \multicolumn{3}{|l|}{ Educational level } \\
\hline Primary & $9(14.3)$ & $4(5.8)$ \\
\hline Secondary & $24(39.7)$ & $23(33.3)$ \\
\hline Tertiary & $10(15.9)$ & $8(11.6)$ \\
\hline Uneducated & $20(31.7)$ & $34(49.3)$ \\
\hline \multicolumn{3}{|c|}{ Employment status } \\
\hline Employed & $12(19.0)$ & $12(17.4)$ \\
\hline Unemployed & $34(53.9)$ & $35(50.7)$ \\
\hline Student & $3(4.8)$ & $4(5.8)$ \\
\hline Other & $14(22.2)$ & $18(26.1)$ \\
\hline
\end{tabular}

\section{ART Regimen of the Patients}

All patients had more than 6 months of antiretroviral treatment. Majority of who were on first-line regimen. The proportion of patients that use different drug combination is presented on table 2. The patients' first-line drugs were zidovudine, lamivudine, nevirapine and tenofovir combinations. The second-line drugs were Lopinavir/ritonavir based combinations as shown on the table.

Table 2: ART Regimen of the patients.

\begin{tabular}{lcc}
\hline $\begin{array}{l}\text { Antiretroviral } \\
\text { combination }\end{array}$ & $\begin{array}{c}\text { Intervention }(\mathbf{N}=\mathbf{6 3}) \\
\text { Total }(\%)\end{array}$ & $\begin{array}{c}\text { Control }(\mathbf{N}=69) \\
\text { Total }(\%)\end{array}$ \\
\hline AZT+3TC+NVP & $40(63.5)$ & $43(62.3)$ \\
TDF+3TC+EFV & $18(28.6)$ & $20(28.9)$ \\
LPV/r+TDF+3TC & $5(7.9)$ & $5(7.2)$ \\
LPV/r+AZT+3TC & $0(0)$ & $1(1.4)$ \\
\hline
\end{tabular}

Key: AZT=Zidovudine, 3TC=Lamivudine, $\mathrm{NVP}=$ Nevirapine, $\mathrm{TDF}=$ Tenofovir, $\mathrm{LPV} / \mathrm{r}=$ Lopnavir/rinonavir.

\section{Patients' CD4 Count at Base-line and After Follow-up}

The CD4 counts of the patients are presented on table 3. At base-line, patients with less than 100 cells $/ \mathrm{mm}^{3}$ was $1(1.6 \%)$ in the intervention group and $2(2.9 \%)$ in the control group. A large proportion of the patients have greater than 350 cells $/ \mathrm{mm}^{3}$ $47(74.6 \%)$ and $47(68.1 \%)$ in the intervention and control group respectively. These values increased after the 24 weeks follow-up as seen from the table.

Table 3: CD4 counts at base-line and after follow-up.

\begin{tabular}{ccccc}
\hline \multirow{2}{*}{$\begin{array}{c}\text { CD4 Count } \\
\text { (cells/mm3) }\end{array}$} & \multicolumn{2}{c}{$\begin{array}{c}\text { Intervention }(\mathbf{N}=63) \\
\text { Total (\%) }\end{array}$} & \multicolumn{2}{c}{$\begin{array}{c}\text { Control }(\mathbf{N}=69) \\
\text { Total (\%) }\end{array}$} \\
\cline { 2 - 5 } & $\begin{array}{c}\text { At base- } \\
\text { line }\end{array}$ & $\begin{array}{c}\text { After } \\
\text { follow-up }\end{array}$ & $\begin{array}{c}\text { At base- } \\
\text { line }\end{array}$ & $\begin{array}{c}\text { After } \\
\text { follow-up }\end{array}$ \\
\hline$<100$ & $1(1.6)$ & $0(0)$ & $2(2.9)$ & $3(4.3)$ \\
$100-200$ & $4(6.3)$ & $0(0)$ & $11(15.9)$ & $7(10.1)$ \\
$201-350$ & $11(17.5)$ & $9(14.3)$ & $9(13.0)$ & $11(15.9)$ \\
$>350$ & $47(74.6)$ & $54(85.7)$ & $47(68.1)$ & $48(69.5)$ \\
\hline
\end{tabular}

\section{Patients' Adherence based on CD4 Count}

$42(66.7 \%)$ of the patients in the intervention group had increase in their CD4 count while in the control group 39(56.5\%) had increase. The increase is presented as percentage increase. Patients with decrease in CD4 count are regarded as no increase and were regarded as having $0 \%$ increase. The mean percentage increase in CD4 count in the intervention group was $36.7 \%$ and $19.12 \%$ in the control group (Table 4). Analysis using Student-t test shows that there was statistically significant difference between the two groups with respect to the rise in CD4 count. $\mathrm{p}=$ 0.007 .

Table 4: Mean percentage increase in CD4 count.

\begin{tabular}{cc}
\hline Group & Increase in CD4 count (\%) \\
\hline Intervention & $36.4 \pm 9.4$ \\
Control & $19.1 \pm 3.3$ \\
\hline Data are mean + SEM, $\mathrm{p}<0.05$ (Student-t test).
\end{tabular}

Data are mean \pm SEM, $\mathrm{p}<0.05$ (Student-t test).

$\mathrm{N}_{\text {Intervention }}=63, \mathrm{~N}_{\text {Control }}=69$

\section{Patients' Adherence based on Self Report}

$47(74.6 \%)$ patients in the intervention group had $95 \%$ or above adherence while $16(25.3 \%)$ had less than $95 \%$ adherence. In the control group, 51(73.9\%) reported $95 \%$ or above increase while $18(26.1 \%)$ had less than $95 \%$. Chi-square test showed no statistical significant difference in the level of adherence between the two groups. $X^{2}=0.012$. 


\section{DISCUSSION}

Poor adherence is a major challenge to antiretroviral therapy. It is now recommended that patients have $95 \%$ adherence in order to maintain sufficient suppression of viral replication and prevent the emergence of resistance. It is therefore of paramount importance device methods to improve patients adherence. The use of mobile phone calls and text messages are being explored in improving adherence. A large proportion of the patients were on zidovudine, Lamivudine and Nevirapine fixed dose combination which is taken twice daily and Tenofovir, Lamivudine and Efavirenz fixed dose combination taken once daily. This simple dosing might have contributed to adherence. Patients on secondline Lopinavir/ritonavir, Tenofovir, Lamivudine combination are few, representing $7.9 \%$ in intervention group and $7.2 \%$ in the control group. The study found that mobile text messages improved patients' adherence to ART by reminding them to take their medications on time and avoid skipping of doses. The patients that received bi-weekly reminder text messages had better increase in their CD4 count after the 24 weeks follow-up period. This finding is consistent with the results of some studies which have successfully utilized mobile based intervention to facilitate adherence to ART. A study found that follow-up telephone calls increased adherence by pill count and self report (Simoni et al., 2003). Another study also got similar findings (Da costa et al., 2012). A randomised trial in the United States utilizing telephone calls for patients on ART reported a significant benefit for adherence but not virologic control (Collier et al., 2005). However, a study in China utilizing mobile phone intervention showed no statistical significant difference in CD4 count increase between the intervention and control (Dongshen et al., 2012). This is inconsistent with the finding of this study. It has been reported that the most popular application of mHealth (e.g. mobile phone technologies) is for improving adherence especially in low and middle income countries. It has also been successfully used to schedule hospital appointments (Perron et al., 2011). It could also be seen that the mobile phone intervention could increase the quality of care since the patients in the intervention group had the opportunity to call the health worker when they have specific therapy problem. The study also showed that patient counselling had contributed to the adherence as both intervention and control groups have good increase in CD4 count after the 24 weeks period of follow-up. This is consistent with a finding that non-adherence was associated with lack of counselling on the importance of adhering to ART (Lal et al., 2010). Also not attending any counselling in the last 6 months has been shown to influence adherence (Sharma et al., 2007). Therefore counselling patients regularly aside the pre-ART counselling would help in improving adherence. However, there are reasons that could cause low levels of CD4 counts as shown in other patients. This could be due to malaria and infected wounds (Chirenda, 1999), Pregnancy (Burns et al., 1996), stress (Verde et al., 1992), malnutrition (Hegde et al., 1999). Patients' self report of adherence showed no significant difference between the intervention and control groups. This could be as a result of exaggeration of adherence by the patients might not have actually attained the $95 \%$ cut off. Other studies reported possible over estimate of adherence using self report (Mc Nabb et al., 2003). Although self report still remains an efficient and simple tool for monitoring patients' adherence. A study has shown that self reported adherence is significantly associated with viral suppression (Arnsten et al., 2001).

\section{CONCLUSION}

It could be concluded from this study that counselling and text message follow-up has improved patients' adherence to ART similar to results found in other parts of Nigeria, other African countries, India and the United States. The present study established that reminder text messages have improved patients' adherence to ART. This mainly targets issues related to forgetfulness and also gives opportunity for patients to interact more with the health workers and also regular patient counselling has improved patients' adherence to ART thereby improve quality of life.

A system that incorporates reminder text messages to all patients with the aim of improving adherence to ART especially in resource-limited settings is recommended.

\section{Financial support and sponsorship: Nil.}

Conflict of Interests: There are no conflicts of interest.

\section{REFERENCES}

Ahmad WA, Amin WA, Aleng NA, Mohamed A. Some Practical Guidelines for Effective Sample-Size Determination in Observational Studies. Aceb International Journal of Science and Technology. 2012; 1(2): 51-53.

Arnsten JH, Demas PA, Farzadegan H, Grant RW, Gourevitch MN, Chang CJ, Buono D, Eckodt H, Howard AA, Shoenbaum EE. Antiretroviral therapy adherence and viral suppression in HIV infected drug users: comparison of self-report and electronic monitoring. Clinical Infectious Diseases. 2001; 32:435-440.

Burns DN, Nourjah P, Minkoff H, Korelitz J, Biggar RJ, Landesman S, Rubinstein A, Wright D, Nugen RP. Changes in CD4 and CD8 cell levels during pregnancy and post partum in women seropositive and seronegative for HIV-1. American Journal of Obstetrics and Gynaecology. 1996; 174(5):1461-1468.

Charles RC and Robert ES. 1997. Modern Pharmacology with Clinical applications $\left(5^{\text {th }} \mathrm{ed}\right) . \quad$ New York, United States. Lippincott. 584.

Chirenda J. Low CD4 count in HIV-negative malaria cases, and normal CD4 count in HIV-positive and malaria negative patients. The Central African JournalofMedicine. 1999; 45(9):248.

Collier AC, Ribaudo H, Mukherjee AL, Feinberg J, Fischl MA, Chesney $\mathrm{M}$. A randomized study of serial telephone call support to increase adherence and thereby improve virologic outcome in persons initiating antiretroviral therapy. Journal of Infectious Diseases. 2005; 192: 1398-406.

Da Costa TM, Barbosa BJ, Gomes E, Costa DA, Siqulem D, de Fetima MH, Filho AC, Pisa TT. Results of a randomized controlled trial to assess the effects of a mobile SMS-based intervention on treatment adherence in HIV/AIDS-infected Brazilian women and impressions and satisfaction with respect to incoming messages. International Journal of Medical Informatics. 2012; 81:257-269. 
Dongsheng H, Rassame S, Edward MN, Virasakdi C, Weibin Z, Xueibin Y. 2013. Effects of a Phone call Intervention to Promote Adherence to Antiretroviral Therapy and Quality of Life of HIV/AIDS patients in Boashan, China:A Randomized Controlled trial.AIDS Research and Treatment. Hindawi Publishing Corporation 3-5.

Hegde HR, Woodman RC, Sankaran K. Nutrients as Modulators of Energy in Acquired Immune Deficiency Syndrome. Journal of Association of Physicians of India.1999. 47(3):318-325.

Horvath T, Azman H, kennedy GE, Rutherford GW. 2012. The Cochrane Collaboration: Mobile Phone Text Messaging For Promoting Adherence To Antiretroviral Therapy in Patients with HIV infection. John Wiley and Sons Ltd 11.

Joint United Nations Program on HIV/AIDS (UNAIDS). 2012. Report on The Global AIDS Epidemic. p8.

Lal V, Kant S, Dewan R, Rai SK, Biswas A. A two-site hospital-based study on factors associated with non-adherence to highly active antiretroviral therapy. Indian Journal of Public Health. 2010; $54: 179-83$

Lester RT, Ritro P, Mills EJ, Kariri A, Karanja S, Chung MH, Jack W, Habyarimana J, Sadatsafavi M, Najafzadeh M, Marra CA, Estambale B, Nyugi E, Ball TB, Thabane L, Gelmon LJ, Kimani J, Ackers M, Plummer FA. 2010. Effect of a Mobile Phone Text Message Service on Antiretroviral Treatment Adherence in Kenya (WelTel): A Randomised Trial.

Maduka O. and Tobin-West CI. Adherence Counselling and Reminder Text Messages Improve Uptake of Antiretroviral Therapy in a Tertiary Hospital in Nigeria. Nigerian Journal of Clinical Practice.2013; 16(3):305-307.

McNabb JJ, Nicolau DP, Stoner JA, Ross J. Patterns of adherence to antiretroviral medications: The value of electronic monitoring. AIDS.2003; 17:1763-1767.

National Agency for the Control of AIDS (NACA) Federal Republic of Nigeria. 2014. Global Press Report. p13.

Perron NJ, Dao MD, Kossovsky MP, Miserez V, Chuard C, Calmy A, Gasoz J. Reduction of missed appointments at an urban primary care clinic: a randomised controlled study. Biomedical Central Family Practice.2011; 11:79.
Pradier C, Bentz L, Spire B, Tourette-Turgis C, Morin M, Souville M, Rebillon M, Fuzibet J, Pesce A, Dellamonica P, and Moatti J. Efficacy of an Educational and Counselling Intervention on adherence to Highly Active Antiretroviral Therapy: French Prospective Controlled Study. HIV Clinical Trials.2003;4(2):121-131. Thomas Land Publishers, Inc.

Sharma M, Singh RR, Laishram P, Kumar B, Nanao H, Sharma C, Ahmed T. Access, adherence, quality and impact of ARV provision to current and ex-injecting drug users in Manipur (India): an initial assessment. International Journal of Drug Policy. 2007; 18:319-325.

Simoni JM, Frick PA, Pantalone DW, Turner BJ. Antiretroviral

Adherence Intervention: A Review of Current Literature and Ongiong Studies. 2003; 11(6):187-188.

Verde TJ, Thomas SG, Moore RW, Shek P, Shephard RJ. Immune responses and increased training of the elite athlete. Journal of Applied Physiology. 1992; 73(4):1494-1499.

\section{How to cite this article:}

Alfa MA, Zezi AU, Gyang SS, Yusuf H, Aliyu IM. Effect of Counselling and Reminder Text Messages Follow-Up on Adherence to Antiretroviral Therapy in Hajiya Gambo Sawaba General Hospital, Zaria, Nigeria. J App Pharm Sci, 2016; 6 (09): 174-178. 